\title{
The Effect of a Boiling Additive on R123 Condensation on a Vertical Integral-Fin Surface
}

\section{Mark A. Kedzierski}

U.S. DEPARTMENT OF COMMERCE

Technology Administration

National Institute of Standards and Technology

Building and Fire Research Laboratory

Gaithersburg, MD 20899

QC

100

.056

N0.6314 



\section{The Effect of a Boiling Additive on R123 Condensation on a Vertical Integral-Fin Surface}

\section{Mark A. Kedzierski}

U.S. DEPARTMENT OF COMMERCE

Technology Administration

National Institute of Standards and Technology

Building and Fire Research Laboratory Gaithersburg, MD 20899

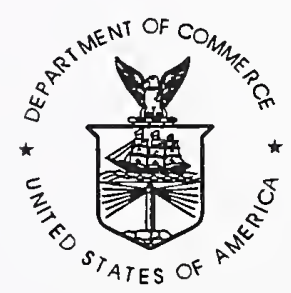

U.S. DEPARTMENT OF COMMERCE William M. Daley, Secretary

TECHNOLOGY ADMINISTRATION Gary R. Bachula, Acting Under Secretary for Technology

NATIONAL INSTITUTE OF STANDARDS

AND TECHNOLOGY

Raymond G. Kammer, Director 



\section{TABLE OF CONTENTS}

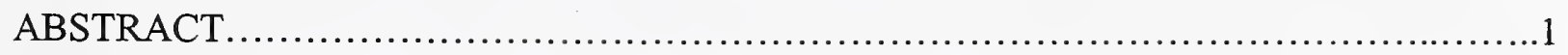

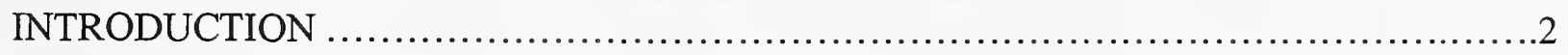

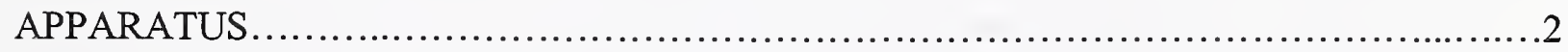

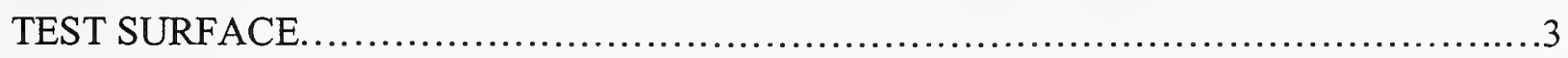

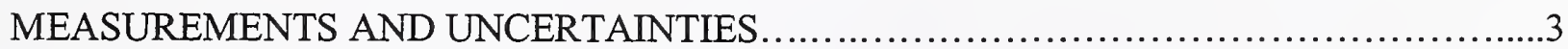

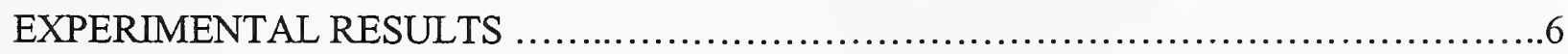

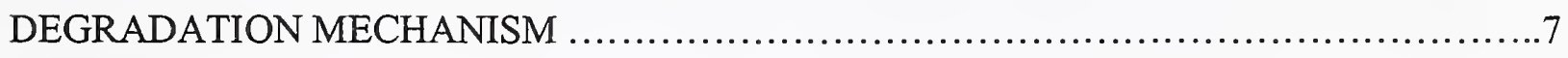

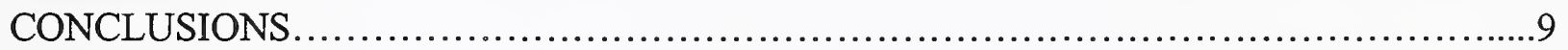

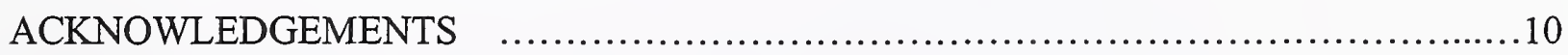

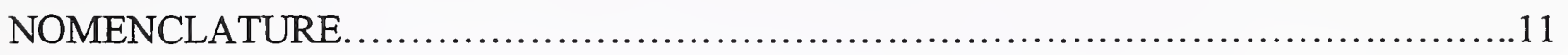

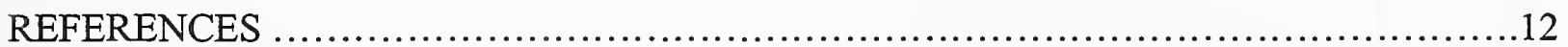





\begin{abstract}
This paper examines the effect of the addition of $0.5 \%$ mass isopentane to R 123 on the vaporspace condensation heat transfer of R123. In a previous study, the pool boiling performance of R123 was improved by adding $0.5 \%$ mass isopentane. Consequently, the impetus of the present study was a desire to quantify the consequence of the boiling additive on the condensation heat transfer performance of pure R123. In this way, the net effect of the additive on the cycle performance of pure R123 can be estimated. The data consisted of the heat flux and the wall temperature difference measurements for pure R123 and R123/isopentane (99.5/0.5) on an integral-trapezoidal-fin surface. The temperature of the saturated vapor was held constant at $313.15 \mathrm{~K}$ for all of the tests. On average, the R123/isopentane mixture exhibited a $4 \%$ smaller heat flux than that of pure R123. Presumably, the degradation was caused by the zeotropic behavior of the mixture, which led to a loss of available driving temperature difference for heat transfer across the liquid film. Considering that the boiling performance was enhanced on average by $10 \%$ with the addition of $0.5 \%$ mass isopentane, isopentane may still be a viable means of improving the cycle performance of R123 despite the $4 \%$ condensation heat transfer degradation.
\end{abstract}

Keywords: Additive, binary mixtures, condensation, enhanced heat transfer, integraltrapezoidal-fin, isopentane, R123, refrigerants, surfactant 


\section{INTRODUCTION}

For the refrigeration and air-conditioning industry, a liquid additive would be an economical means to reduce manufacturing and/or operating costs. For example, a liquid additive for 1,1dichloro-2,2,2-trifluoroethane (R123) would enable existing water chillers to operate more efficiently or enable new water chillers to meet the same duty with fewer tubes. However, the economic benefit of additives that enhance boiling heat transfer can be realized only when the additive does not significantly degrade the condensation heat transfer.

Kedzierski (1999) measured a significant enhancement of R123 pool boiling with the addition of $1 \%$ and $2 \%$ hexane by mass to R123. He used the Gibbs adsorption equation and the Young and Dupre equation to speculate that the boiling heat transfer enhancement of R123 by the addition of hexane was caused by an accumulation of hydrocarbon at the boiling surface. In essence, the greater concentration of hydrocarbon or "excess layer" at the heat transfer surface caused a reduction of the surface energy between the solid surface and the liquid. The existence of an excess layer at the liquid-solid interface is analogous to the existence of a surfactant induced excess layer at a liquid-vapor interface. Consequently, the hydrocarbon is not a typical surfactant because it accumulates at the solid-liquid interface rather than the liquid-vapor interface. However, the reduction in the liquid-solid surface energy results in a similar reduction in bubble departure diameter that occurs with a conventional surfactant. As a consequence of the bubble size reduction, the active site density increases. A boiling heat transfer enhancement existed when a favorable balance between an increase in site density and a reduction in bubble size occurred.

In another boiling additive study, Kedzierski (1998) speculated that fouling caused a more modest improvement in the heat flux of R123 with the addition of isopentane and hexane. Overall, the R 123 /isopentane (99.5/0.5) by mass mixture exhibited a $10 \%$ heat flux enhancement for heat fluxes within the range of $10 \mathrm{~kW} / \mathrm{m}^{2}$ to $90 \mathrm{~kW} / \mathrm{m}^{2}$. Similarly, the $\mathrm{R} 123 /$ hexane $(99.5 / 0.5)$ mixture showed an overall $4 \%$ and a maximum of $13 \%$ heat flux enhancement over that of pure R123.

The purpose of the present study is to determine the effect of a boiling additive on the condensation heat transfer performance of R123. A boiling additive is unlikely to be commercially viable if it causes a heat transfer degradation in the condenser that more than offsets the heat transfer enhancement in the evaporator. Assuming that isopentane is a better additive than hexane for the enhancement of R123 boiling on all surfaces, isopentane may potentially produce the greatest net heat transfer improvement between the condenser and the evaporator. Based on that premise, the vapor-space condensation heat transfer performance of pure R123 and an R123/isopentane (99.5/0.5) by mass mixture were measured on a vertical, trapezoidal fin surface.

\section{APPARATUS}

Figure 1 shows a schematic of the apparatus that was used to measure the vapor-space condensation heat transfer data of this study. Specifically, the apparatus was used to measure the vapor saturation temperature $\left(T_{v}\right)$, the average condensation heat flux $\left(q^{\prime \prime}\right)$, and the wall temperature $\left(T_{w}\right)$ of the test surface at the root of the fin. The three principal components of the apparatus were test chamber, post condenser, and boiler. The internal dimensions of the test 
chamber were approximately $254 \mathrm{~mm} \times 200 \mathrm{~mm} \times 130 \mathrm{~mm}$. The boiler was charged with approximately $10 \mathrm{~kg}$ of R123. Hot city water flowed inside the tubes of the boiler to heat the test refrigerant on the shell-side of the boiler. The test section was visible through three, flat quartz windows. The opposing side of the finned condensing test surface was cooled with high velocity $(2.5 \mathrm{~m} / \mathrm{s})$ water flow. Varying the temperature of the cooling water varied the heat flux of the test section. The vapor produced by the boiler was condensed by the post condenser and the test section and returned by gravity to the liquid pool. The post condenser was identical to the shelland-tube boiler; however, chilled water flowed inside the tubes while the vapor condensed on the outside of the tubes. The duty of the boiler and the post condenser were significantly large so that a wide variation in the duty of the test surface would not affect the saturation pressure of the test apparatus. The purger and the desiccant filter removed non-condensible gases and water, respectively, from the test refrigerant after charging and before testing.

To reduce the errors associated with the saturation temperature measurement, the saturation temperature of the vapor was measured with two $450 \mathrm{~mm}$ long $1.6 \mathrm{~mm}$ diameter stainless steel sheathed thermocouples. The small diameter provided for a relatively rapid response time. Approximately $180 \mathrm{~mm}$ of each thermocouple length was exposed to the vapor of the test chamber. The portion of each thermocouple that was in the test chamber was shielded with a 6 $\mathrm{mm}$ diameter stainless steel tube and was in contact with the saturated refrigerant vapor. The tips of the two thermocouples were placed near the lower edge of the test plate and approximately $60 \mathrm{~mm}$ and $95 \mathrm{~mm}$, respectively, from the front of it.

\section{TEST SURFACE}

Figure 2 shows the oxygen-free high-conductivity (OFHC) copper integral-trapezoidal-fin test plate used in this study. The integral-trapezoidal-fin surface in this study was machined directly onto the top of the test plate by electric discharge machining (EDM). Figure 3 shows a drawing of the fin cross section. The fin pitch was $1.36 \mathrm{~mm}$. The surface had nominally 746 fins per meter oriented along the long axis of the plate. The ratio of the surface area to the projected area of the surface was 2.87 . The ratio of the fin area $\left(A_{f}\right)$ to the total area $\left(A_{o}\right)$ was 0.74 . The fin-tip width and the fin-height were $0.24 \mathrm{~mm}$ and $1.53 \mathrm{~mm}$, respectively.

\section{MEASUREMENTS AND UNCERTAINTIES}

The standard uncertainty $\left(u_{i}\right)$ is the positive square root of the estimated variance $u_{i}^{2}$. The individual standard uncertainties are combined to obtain the expanded uncertainty $(U)$. The expanded uncertainty is commonly referred to as the law of propagation of uncertainty with a coverage factor. All measurement uncertainties are reported for a $95 \%$ confidence interval.

The copper-constantan thermocouples and the data acquisition system were calibrated against a glass-rod standard platinum resistance thermometer (SPRT) and a reference voltage to a residual standard deviation of $0.013 \mathrm{~K}$. The NIST Thermometry Group calibrated the fixed SPRT to two fixed points having expanded uncertainties of $0.06 \mathrm{mK}$ and $0.38 \mathrm{mK}$. A quartz thermometer, which was calibrated with a distilled ice bath, agreed with the SPRT temperature to within approximately $0.003 \mathrm{~K}$. No correlation was found to exist between the measured thermocouple electromotive force (EMF) and a measured $1 \mathrm{mV}$ reference. Consequently, there was no measurable drift in the acquisition voltage measurement over a month period. Before each test run, the measurements of a thermocouple in the bath were compared with the SPRT. The 
median absolute difference between the thermocouple and the SPRT was $0.02 \mathrm{~K}$ over the duration of the entire study. Considering the fluctuations in the saturation temperature during the test and the standard uncertainties in the calibration, the expanded uncertainty of the average saturation temperature was no greater than $0.04 \mathrm{~K}$. Consequently, it is believed that the expanded uncertainty of the temperature measurements was less than $0.1 \mathrm{~K}$. The saturation temperature was also obtained from a pressure transducer measurement with an expanded uncertainty of less than $0.03 \mathrm{kPa}$. The expanded uncertainty of the saturation temperature from a regression (with a residual standard deviation of $0.6 \mathrm{mK}$ ) of equilibrium data (Morrison and Ward, 1991) for R123 was $0.17 \mathrm{~K}$. The saturation temperature obtained from the thermocouple and the pressure measurement nearly always agreed within $\pm 0.17 \mathrm{~K}$ for the pure $\mathrm{R} 123$ data.

Figure 2 shows the coordinate system for the 20 wells where individual thermocouples were force-fitted into the side of the test plate. The wells were $16 \mathrm{~mm}$ deep to reduce conduction errors. Using a method given by Eckert and Goldstein (1976), errors due to heat conduction along the thermocouple leads were estimated to be well below $0.01 \mathrm{mK}$. The origin of the coordinate system was centered on the surface with respect to the $y$-direction at the root of the fin. Centering the origin in the y-direction improved the accuracy of the wall heat flux and temperature calculations by reducing the number of fitted constants involved in these calculations. The $\mathrm{x}$-coordinate measures the distance normal to the heat transfer surface. The $\mathrm{y}$ coordinate measures the distance perpendicular to the $\mathrm{x}$-coordinate. The thermocouples were arranged in four sets of five aligned in the $\mathrm{x}$-direction. Following a procedure given by Kedzierski and Worthington (1993), the size and arrangement of the thermocouple wells were designed to minimize the errors in the wall temperature and temperature gradient measurement.

The heat flux and the wall temperature were obtained by regressing the measured temperature distribution of the block to the governing two-dimensional conduction equation (Laplace equation). In other words, rather than using the boundary conditions to solve for the interior temperatures, the interior temperatures were used to solve for the boundary conditions following a backward stepwise procedure given in Kedzierski (1995).

A backward stepwise regression was used to determine the best model or the significant terms of the solution to the Laplace equation in rectangular coordinates for each data point. Most infinite series solutions should converge within nine terms. The backward stepwise method began by regressing the first nine terms of the Laplace infinite series solution to the twenty measured plate temperatures:

$$
\begin{aligned}
& T=C_{0}+C_{1} x+C_{2} y+C_{3}\left(x^{2}-y^{2}\right)+2 C_{4} x y+C_{5} x\left(x^{2}-3 y^{2}\right) \\
& +C_{6} y\left(3 x^{2}-y^{2}\right)+C_{7}\left(x^{4}-6 x^{2} y^{2}+y^{4}\right)+4 C_{8}\left(x^{3} y-x y^{3}\right)
\end{aligned}
$$

The above "full" model was reduced to its significant terms by removing terms with t-values less than two while maintaining the original residual standard deviation of the full model. Terms were removed one at a time. Regression of the 20 temperatures was done after each term with the smallest t-value was removed. Table 1 provides an overview of the various two-dimensional conduction models that were used to reduce the measured temperatures to heat fluxes and wall temperatures. 
Fourier's law and the fitted constants $\left(C_{0}, C_{1}, \ldots C_{n}\right)$ were used to calculate the average heat flux $\left(q^{\prime \prime}\right)$ normal to and evaluated at the heat transfer surface, e.g.:

$$
q^{\prime \prime}=\left(\frac{1}{L_{y}} \int_{\frac{L_{y}}{2}}^{\frac{L_{y}}{2}} k \frac{\partial T}{\partial x} d y\right)_{x=0}
$$

For most models, the above equation reduces to:

$$
q^{\prime \prime}=\bar{k} C_{1}
$$

where $\bar{k}$ is the average thermal conductivity along the surface of the plate, and $L_{y}$ is the length of the heat transfer surface as shown in Fig. 2.

The average wall temperature $\left(T_{w}\right)$ was calculated by integrating the local wall temperature:

$$
T_{w}=\left(\frac{1}{L_{y}} \int_{\frac{L_{y}}{2}}^{\frac{L_{y}}{2}} T d y\right)_{x=0}
$$

Figure 4 shows the uncertainty in the temperature of the surface at the root of the fin $\left(E_{T w}\right)$ as a function of the heat flux for the two test fluids on the trapezoidal fin surface. The uncertainty in $T_{w}$ was calculated from the regression of the solution to Laplace's equation. The uncertainties in the wall temperature for the two fluids are consistent with one another increasing from approximately $0.012 \mathrm{~K}$ at $2 \mathrm{~kW} / \mathrm{m}^{2}$ to $0.034 \mathrm{~K}$ at $60 \mathrm{~kW} / \mathrm{m}^{2}$. The average random error in the wall temperature difference -- $\Delta T_{s}=T_{v}-T_{w}$-- was within $0.04 \mathrm{~K}$ for all test heat fluxes.

Figure 5 shows the relative (percent) uncertainty of the heat flux $\left(E_{q^{\prime \prime}}\right)$ as a function of the heat flux. Siu et al. (1976) estimated the uncertainty in the thermal conductivity of OFHC copper to be about $2 \%$ to $3 \%$ by comparing round-robin experiments. Considering this, the relative expanded uncertainty in $q$ " was greatest at the lowest heat fluxes, being between $4 \%$ and $9 \%$ for heat fluxes less than $10 \mathrm{~kW} / \mathrm{m}^{2}$. In general, the $E_{q^{\prime \prime}}$ appears to remain within $3 \%$ and $4 \%$ for heat fluxes greater than $15 \mathrm{~kW} / \mathrm{m}^{2}$.

The R123/isopentane (99.5/0.5) by mass mixture was prepared by first charging approximately $90 \%$ of a known mass of R123 into the boiler. Next, a measured weight of spectrophotometric grade isopentane was injected with a syringe through a valve in the side of the boiler (see Fig. 1). The remaining R123 charge was used to flush the valve and connecting tubes and also to assist in mixing the charge. The mass fraction was determined from the masses of the charged components. The uncertainty of the composition measurement for plus or minus three standard deviations was approximately $0.02 \%$, e.g., the range of a $0.5 \%$ composition was between 0.48 $\%$ and $0.52 \%$. 


\section{EXPERIMENTAL RESULTS}

The heat flux was varied from approximately $65 \mathrm{~kW} / \mathrm{m}^{2}$ to $2 \mathrm{~kW} / \mathrm{m}^{2}$ to simulate a range of operating conditions for R123 condensers equipped with enhanced tubes. All vapor-space condensation tests were taken at $313.15 \mathrm{~K}$ saturated conditions. Nearly no condensate retention was observed on the surface for all test heat fluxes. Table 2 presents the measured heat flux and wall temperature difference for all of the data of this study. Table 3 gives the number of test days and data points for each fluid.

Figures 6 and 7 are plots of the measured heat flux $\left(q^{\prime \prime}\right)$ versus the measured wall temperature difference $\left(T_{v}-T_{w}\right)$ for pure R123 and R123/isopentane (99.5/0.5), respectively. Each fluid was tested over five days at a saturated vapor temperature of $313.15 \mathrm{~K}$ on the vertical integraltrapezoidal-fin surface. For the most part, one day's test covered only a portion of heat fluxes from $60 \mathrm{~kW} / \mathrm{m}^{2}$ to $2 \mathrm{~kW} / \mathrm{m}^{2}$. The solid line is a cubic best-fit regression or estimated mean of the data. Table 4 gives the constants for the cubic regression of the wall temperature difference versus the heat flux for each test fluid. The residual standard deviation of the regressions representing the proximity of the data to the mean - for pure R123 and the mixture about the mean was $0.025 \mathrm{~K}$ and $0.05 \mathrm{~K}$, respectively. The dashed lines to either side of the mean represent the lower and upper $95 \%$ simultaneous (multiple-use) confidence intervals for the mean. The expanded uncertainty of the estimated mean wall temperature difference for pure $\mathrm{R} 123$ and the mixture is approximately $0.015 \mathrm{~K}$ and $0.04 \mathrm{~K}$, respectively.

Figure 7 compares the mean of the heat flux versus $\Delta T_{s}$ for pure R123 to the mean and the data of that for the R123/isopentane (99.5/0.5) mixture. The heat flux and the wall temperature difference for both fluids decrease as they both approach zero. The R123 mean is parallel to the mean for the R123/isopentane (99.5/0.5) mixture. For a given heat flux, the R123 $\Delta T_{s}$ is approximately $0.1 \mathrm{~K}$ less than that of R123/isopentane (99.5/0.5). Consequently, the mixture experiences a heat transfer degradation as compared to pure R123.

Figure 8 quantifies the heat transfer degradation of the mixture relative to pure $\mathrm{R} 123$. The figure plots the ratio of the mixture to the pure R123 heat flux $\left(q^{\prime \prime}{ }_{m} / q^{\prime \prime}{ }_{p}\right)$ versus the pure R123 heat flux $\left(q^{\prime \prime}\right)$ at the same wall temperature difference. A heat transfer degradation exists where the heat flux ratio is less than one and where the $95 \%$ simultaneous confidence intervals (depicted by the dotted lines) do not include the value one. As the figure shows, the R123/isopentane (99.5/0.5) mixture exhibits approximately a $5 \%$ to $1.5 \%$ degradation for heat fluxes between $20 \mathrm{~kW} / \mathrm{m}^{2}$ and $65 \mathrm{~kW} / \mathrm{m}^{2}$. A sharp $5 \%$ to $10 \%$ loss in heat flux occurs from $20 \mathrm{~kW} / \mathrm{m}^{2}$ to $10 \mathrm{~kW} / \mathrm{m}^{2}$. For $99.5 \%$ confidence, the relative boiling performance of the $99.5 / 0.5$ mixture and pure R123 for heat fluxes less than $10 \mathrm{~kW} / \mathrm{m}^{2}$ is indeterminate. Overall, the R123/isopentane $(99.5 / 0.5)$ mixture exhibited a $4 \%$ heat transfer degradation from $10 \mathrm{~kW} / \mathrm{m}^{2}$ to $65 \mathrm{~kW} / \mathrm{m}^{2}$. The relatively small heat transfer degradation illustrates that the addition of $0.5 \%$ mass isopentane to R 123 may improve cycle performance because, as shown by Kedzierski (1998), the evaporator performance improves by $10 \%$ overall with the addition of $0.5 \%$ mass isopentane.

It is likely that the R123/isopentane mixture will exhibit less condensate retention when condensed on a horizontal integral-finned tube than it would for pure R123. This is because the 
additive causes a reduction in either the solid-liquid or the liquid-vapor surface-tension. The uncertainty in which surface tension is reduced is due to the difference between the predicted surface tensions of R123 $(0.0134 \mathrm{~N} / \mathrm{m})$ and that of isopentane $(0.0127 \mathrm{~N} / \mathrm{m})$ being within the uncertainty of the prediction. Consequently, the isopentane may accumulate at the liquid-vapor interface or at the solid-liquid interface depending on the relative magnitude of the surface tensions for the two fluids. In either case, the reduction in a surface tension will cause a reduction in the amount of liquid hold-up on the tube. Consequently, it is likely that isopentane may benefit the cycle performance of R123 systems with horizontal integral-fin tubes.

Figure 9 shows the traditional log-log plot of the measured heat transfer coefficient versus the measured wall temperature difference. The heat transfer coefficient was calculated from:

$$
h=\frac{q^{\prime \prime}}{\eta \Delta T_{s}}
$$

where the surface efficiency $(\eta)$ was calculated from the fin efficiency $\left(\eta_{f}\right)$ and a surface area ratio as:

$$
\eta=1-\left(1-\eta_{f}\right) \frac{A_{f}}{A_{o}}=0.8152+3.718 \times 10^{-6} q^{\prime \prime}\left(\frac{\mathrm{W}}{\mathrm{m}^{2}}\right)-3.618 \times 10^{-11} q^{\prime \prime 2}
$$

The fin efficiency was calculated using the rectangular, insulted fin-tip solution given by Holman (1981). Equation 5 also gives the correlation of the surface efficiency that was obtained from the data. The surface efficiency varied from 0.82 at $2 \mathrm{~kW} / \mathrm{m}^{2}$ to 0.91 at $60 \mathrm{~kW} / \mathrm{m}^{2}$. The correlation of the fin efficiency can be used with the correlation for the heat flux given in Table 4 to obtain mean values for the heat transfer coefficient.

Figure 9 shows that the heat transfer coefficient increases with decreasing $\Delta T_{s}$ due to decreasing condensate film thickness with decreasing $\Delta T_{s}$. As expected, most of the heat transfer coefficients for the R123/isopentane mixture are less than that of pure R123. The heat transfer coefficients for R123/isopentane $(99.5 / 0.5)$ for $\Delta T_{s}<1$ are significantly less than that of pure R123. This $\Delta T_{s}$ region corresponds to the indeterminate region of the $q^{\prime \prime}{ }_{m} / q^{\prime \prime} p$ plot where the uncertainties were very large. Consequently, it is believed that the uncertainties of these three R123/isopentane (99.5/0.5) data points are significantly large that the data should be ignored.

\section{DEGRADATION MECHANISM}

The heat transfer degradation shown in Fig. 8 is primarily caused by the zeotropic behavior of the R123/isopentane (99.5/0.5) mixture. For example, only $2 \%$ of the degradation can be attributed to the difference between the fluid properties of the mixture and the pure component. That is to say, a $0.1 \%$ degradation was predicted with the Nusselt analysis when only the thermodynamic and transport properties of each fluid were considered. Accordingly, the following is a discussion of the zeotropic behavior of the mixture and its consequences on the condensation heat transfer. 
One way to illustrate the zeotropic behavior of a mixture is with the equilibrium phase diagram. The phase diagram is a plot of the saturated vapor and the saturated liquid temperatures $\left(T_{s}\right)$ versus the mass fraction of the more volatile component $\left(\mathrm{x}_{\mathrm{m}}\right)$. The saturated vapor temperature and the saturated liquid temperatures of the mixture are the dew point line and the bubble point line, respectively.

Figure 10 shows the equilibrium phase diagram for the R123/isopentane $(99.5 / 0.5)$ mixture at a fixed pressure of $155.42 \mathrm{kPa}$ for two different interaction parameters $(f): f=0.038$ and $f=0.048$ represented by the solid and broken line, respectively. The equilibrium diagrams were obtained from the Carnahan-Starling-DeSantis (CSD) equation of state, which was modified by Morrison and McLinden (1986). The interaction parameter accounts for the non-ideal equilibrium behavior of the mixture. McLinden (1996) recommended an interaction parameter of 0.038 for the $\mathrm{R} 123 /$ isopentane mixture. The $f=0.038$ was preliminarily verified with saturated R123/isopentane (99.5/0.5) temperature and pressure data from the condensing apparatus.

Namely, the measured pressure and the pressure predicted from the CSD equation of state with $f$ $=0.038$ differed by approximately $0.4 \mathrm{kPa}$. The sensitivity of the CSD model predictions to the interaction coefficient was investigated with an interaction parameter of 0.048 . For example, the azeotropic temperature for the CSD model with $f=0.048$ is approximately $1 \mathrm{~K}$ lower than that for the CSD model with $f=0.038$. Also, the difference between the measured and predicted pressures increased to approximately $0.65 \mathrm{kPa}$ when an interaction parameter of 0.048 was used. However, even though the uncertainty of the pressure measurement was $0.14 \mathrm{kPa}$, it cannot be stated with much confidence that 0.038 is a more accurate interaction parameter than that of 0.048. The reason for this is that the equilibrium data that was used to verify the interaction parameter was only for one composition at a single state point and that the interaction parameter was predicted by theory. In other words, it is reasonable to assume that the uncertainty of the interaction parameter may be large enough to include 0.038 and 0.048 as plausible f's.

Although the entire equilibrium diagram is given, only the circled region shown in Fig. 10 is relevant for this study. Consequently, Fig. 11 focuses on the 0.975 to 1.0 mass fraction range of the $\mathrm{R} 123$ /isopentane equilibrium diagram for $f=0.038$. Figure 11 identifies pertinent state points with filled circles. For example, the charged mass fraction of the liquid $(0.995)$ is the composition if the entire mass of the charge were condensed to liquid. The liquid composition in the boiler differs from that of the charged composition because the vapor occupies most of the volume of the test apparatus giving an effective equilibrium quality in the test apparatus of approximately $20 \%$. As a result, the liquid mass fraction in the boiler shifts to 0.996 while the vapor mass fraction in the test chamber shifts to 0.993 at the test temperature of $313.15 \mathrm{~K}$. If the vapor in the test chamber could be completely condensed, the temperature and the mass fraction of the liquid would be $313.05 \mathrm{~K}$ and 0.993 , respectively. The temperature difference between the saturated vapor $(313.15 \mathrm{~K})$ and the saturated liquid $(313.05 \mathrm{~K})$ in the test chamber represents the range of possible values for the liquid-vapor interface temperature of the condensing film. The range of possible temperatures is also referred to as the temperature glide.

Figure 12 shows a cross section of a condensing liquid film on a vertical plate with a liquidvapor interface temperature of $T_{i}$. Of all the parameters used to model the condensation of mixtures, the $T_{i}$ is one of the most important but yet the most illusive modeling parameter. As stated by Colburn and Drew (1937) and Sparrow and Marschall (1969), the condensation process 
of both the mixture and the pure component is governed by the magnitude of $T_{i}$. Modeling the condensation process of a pure fluid is relatively simple because the liquid vapor interface temperature is nearly equal to that of the saturated vapor $\left(T_{v}\right)$. For a mixture, modeling is much more difficult because $T_{i}$ is determined by the magnitude of the vapor concentration gradient adjacent to the liquid film. As a result, the liquid-vapor interface temperature is less than $T_{v}$ at some unknown temperature between the dew point and the bubble point temperatures.

For the R123/isopentane (99.5/0.5) mixture, Fig. 11 shows the liquid-vapor interface temperature can be as much as $0.1 \mathrm{~K}$ less than the saturated vapor temperature. This implies that the temperature difference between the saturated vapor and the wall for the mixture $\left(\Delta T_{s m}\right)$ can be as much as $0.1 \mathrm{~K}$ greater than that for the pure fluid $\left(\Delta T_{s p}\right)$ for the same heat flux. However, unlike the pure fluid, not all of $\Delta T_{s m}$ is available for phase change. The additional temperature drop from the vapor to the liquid-vapor interface $\left(T_{v}-T_{i}\right)$ is essentially lost to sensible cooling. The loss of temperature difference can be indirectly measured from the difference between the $\Delta T_{s}$ 's of the mixture and pure $q$ "versus $\Delta T_{s}$ relationships for fixed heat flux as shown in Fig. 13. This is true if it is assumed, as stated by Colburn and Drew (1937), that the temperature drop across the liquid film governs the condensation process. Here, the $q^{\prime \prime}$ versus $\Delta T_{s}$ for pure R123 correctly represents the magnitude of the heat flux through the condensing film for a given temperature drop across the liquid film and for given fluid properties. Recall that the fluid properties governing the heat transfer of the mixture and pure R123 are nearly the same resulting in only a $0.1 \%$ difference in the heat flux.

Figure 13 plots the difference in the wall temperature differences for the mixture and pure R123 $\left(\Delta T_{m}-\Delta T_{p}\right)$ versus the heat flux. The $\Delta T_{m}-\Delta T_{p}$, which is equivalent to $T_{v}-T_{i}$, varies between approximately $0.14 \mathrm{~K}$ and $0.8 \mathrm{~K}$ with an average value of $0.12 \mathrm{~K}$. Two broken lines show the temperature glide of $0.1 \mathrm{~K}$ and $0.18 \mathrm{~K}$ as predicted by the CSD equation of state using 0.038 and 0.048 as interaction coefficients, respectively. The $95 \%$ confidence interval for $\Delta T_{m}-\Delta T_{p}$, which is depicted by the shaded region, encompasses the predicted temperature glides for most heat fluxes. This illustrates that it would be consistent with an equation of state, given the uncertainty in the interaction coefficient and the uncertainty in the heat transfer measurements, for the value of liquid-vapor interface temperature of the R123/isopentane $(99.5 / 0.5)$ film to be such that it would be responsible for the entire heat transfer degradation. Consequently, all of the heat transfer degradation associated with the R123/isopentane mixture can be attributed to a loss of driving temperature difference $\left(T_{v}-T_{i}\right)$.

\section{CONCLUSIONS}

Vapor-space condensation heat transfer data for pure R123 and an R123/isopentane mixture were measured to examine the effect of the addition of $0.5 \%$ mass isopentane to R123 on the heat transfer performance. The condensation performance of R123 on an integral-trapezoidal-fin surface was degraded as much as $10 \%$ by adding $0.5 \%$ mass isopentane. Overall, the R123/isopentane (99.5/0.5) mixture exhibited a $4 \%$ heat transfer degradation from $10 \mathrm{~kW} / \mathrm{m}^{2}$ to $65 \mathrm{~kW} / \mathrm{m}^{2}$. The condensation degradation mechanism is presumably due to a loss of available driving temperature difference due to the mass transfer resistance in the vapor phase. Given that it was shown in a previous study that the boiling perform was enhanced on average by $10 \%$ with 
the addition of $0.5 \%$ mass isopentane, isopentane may still be a viable means of improving the cycle performance of R123 despite the $4 \%$ condensation heat transfer degradation.

\section{ACKNOWLEDGEMENTS}

This work was jointly funded by NIST and the U.S. Department of Energy (project no. DE-0195CE23808.000 modification \#A004) under Project Manager Esher Kweller. Thanks go to the following NIST personnel for their constructive criticism of the first draft of the manuscript: Dr. V. Payne, Dr. J. Yang, and Mrs. J. Land. The author would also like to express appreciation to Mr. G. Glaeser and Mr. S. Nolan for their help with the rig construction and data collection. Furthermore, the author extends appreciation to Dr. E. Lagergren for consultations on the uncertainty analysis. 


\section{NOMENCLATURE}

\section{English Symbols}

A surface area (m)

$C \quad$ regression constant (Eq. 1)

$B$ regression constant (Table 4)

$E_{T w} \quad$ expanded uncertainty in the wall temperature (K)

$E_{q^{\prime \prime}} \quad$ relative expanded uncertainty (\%) in heat flux measurement

$e \quad$ height of fin from tip to root (m)

$f \quad$ interaction coefficient

$h \quad$ heat transfer coefficient $\left(\mathrm{W} / \mathrm{m}^{2} \bullet \mathrm{K}\right)$

$k \quad$ thermal conductivity $(\mathrm{W} / \mathrm{m} \bullet \mathrm{K})$

$L_{y} \quad$ length of test surface in $\mathrm{y}$-direction (m)

$q^{\prime \prime} \quad$ average wall heat flux $\left(\mathrm{W} / \mathrm{m}^{2}\right)$

$T \quad$ temperature $(\mathrm{K})$

$T_{w} \quad$ temperature of surface at root of fin (K)

$U$ expanded uncertainty

$u_{i} \quad$ standard uncertainty

$x \quad$ test surface coordinate, Fig. 2 (m)

$X \quad$ model term (Table 1)

$x_{m} \quad$ mass fraction

$y \quad$ test surface coordinate, Fig. 2 (m)

\section{Greek Symbols}

$\Delta T \quad$ wall temperature difference: $\mathrm{T}_{\mathrm{v}}-\mathrm{T}_{\mathrm{w}},(\mathrm{K})$

$\eta \quad$ surface efficiency

\section{$\underline{\text { Subscripts }}$}

$f \quad$ fin

$i \quad$ liquid-vapor interface

$l \quad$ liquid

$m$ mixture

$o \quad$ total

$p \quad$ pure $\mathrm{R} 123$

$s \quad$ saturated liquid or vapor state

$v \quad$ saturated vapor state

\section{$\underline{\text { Superscripts }}$}

- average 


\section{REFERENCES}

Colburn, A. P., and Drew, T. B., 1937, "The Condensation of Mixed Vapors," Trans. AICHE, Vol. 33., pp. $197-215$.

Eckert, E. R. G., and Goldstein, R. J., 1976, Measurements in Heat Transfer, Hemisphere, Washington, D.C., 2nd ed., pp. 9-11.

Holman, J. P., 1981, Heat Transfer, $5^{\text {th }}$ ed., McGraw-Hill, New York, p. 41.

Kedzierski, M. A., 1999, "Enhancement of R123 Condensation by the Addition of N-Hexane," Journal of Enhanced Heat Transfer, Vol. 6, No. 3.

Kedzierski, M. A., 1998, "Enhancement of R123 Pool Boiling by the Addition of Hydrocarbons," NISTIR 6244, U.S. Department of Commerce, Washington, D.C.

Kedzierski, M. A., 1995, "Calorimetric and Visual Measurements of R123 Condensation on Four Enhanced Surfaces," NISTIR 5732, U.S. Department of Commerce, Washington, D.C.

Kedzierski, M. A., and Worthington, J. L. III, 1993, "Design and Machining of Copper Specimens with Micro Holes for Accurate Heat Transfer Measurements," Experimental Heat Transfer, Vol. 6. pp. 329-344.

McLinden, M. O., 1996. Private communications, National Institute of Standards and Technology, Boulder, CO.

Morrison, G, and McLinden, M. O., 1986, "Application of a Hard Sphere Equation of State to Refrigerants and Refrigerant Mixtures," NBS Technical Note 1226, U.S. Dept. of Commerce, Washington, D.C.

Morrison, G, and Ward, D. K., 1991, "Thermodynamic Properties of Two Alternative Refrigerants: 1,1-Dichloro-2,2,2-Trifluoroethane (R123) and 1,1,1,2-Tetrafluoroethane (R134a)," Fluid Phase Equilibria, Vol. 62, pp. 65-86.

Siu, M. C. I., Carroll, W. L., and Watson, T. W., 1976, "Thermal Conductivity and Electrical Resistivity of Six Copper-Base Alloys," NBSIR 76-1003, U.S. Department of Commerce, Washington, D.C.

Sparrow, E. M., and Marschall, E., 1969, "Binary, Gravity-Flow Film Condensation," J. Heat Transfer, Vol. 5, pp 205-211. 
Table 1 Conduction model choice

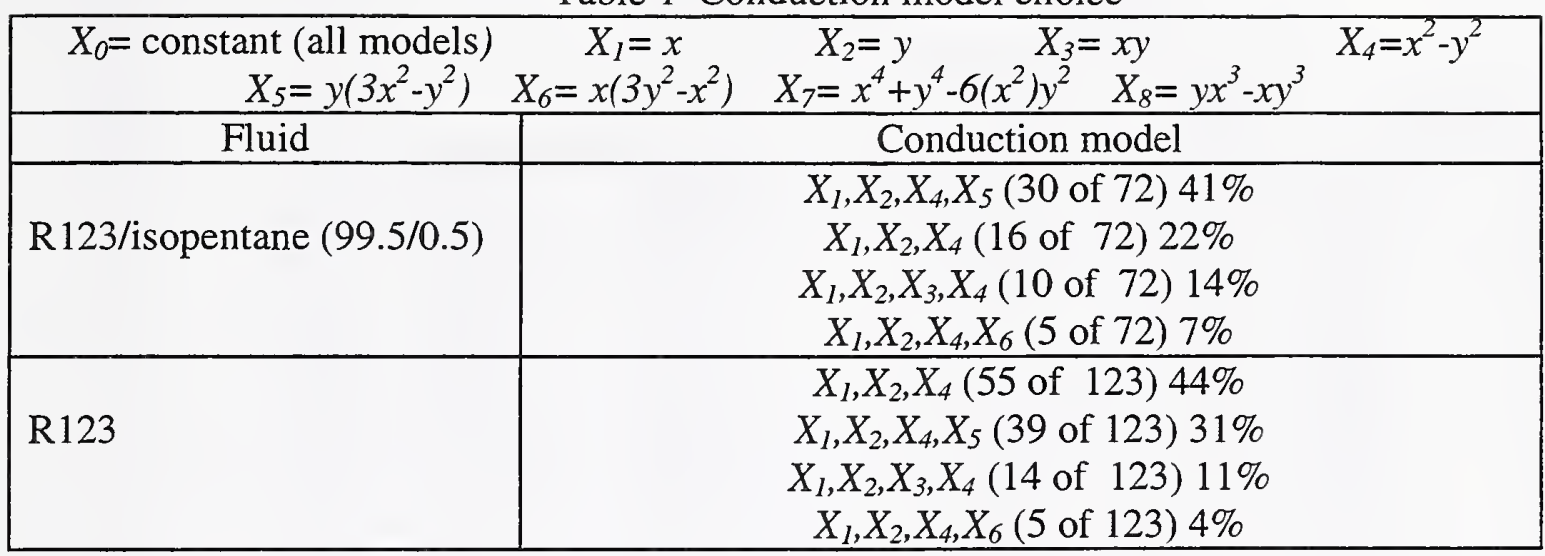


Table 2 Condensation data

\begin{tabular}{|c|c|}
\hline \multicolumn{2}{|c|}{$\begin{array}{c}\text { Pure R123 } \\
\text { File: } 123 \text { cond.dat }\end{array}$} \\
\hline$\Delta T_{s}(\mathrm{~K})$ & $q^{\prime \prime}\left(W / m^{2}\right)$ \\
\hline 5.274 & 54794.7 \\
\hline 5.243 & 54617.1 \\
\hline 5.268 & 54689.1 \\
\hline 5.219 & 54467.3 \\
\hline 4.337 & 46455.7 \\
\hline 4.280 & 46287.9 \\
\hline 4.218 & 45722.2 \\
\hline 4.228 & 45887.9 \\
\hline 2.551 & 30782.6 \\
\hline 2.560 & 30979.5 \\
\hline 2.564 & 30898.0 \\
\hline 2.571 & 31031.8 \\
\hline 2.575 & 31244.5 \\
\hline 2.042 & 26084.2 \\
\hline 6.006 & 60717.1 \\
\hline 5.989 & 60575.3 \\
\hline 6.044 & 61027.7 \\
\hline 6.056 & 61112.9 \\
\hline 6.057 & 61131.5 \\
\hline 5.809 & 57842.0 \\
\hline 5.766 & 58523.4 \\
\hline 5.713 & 57665.8 \\
\hline 5.420 & 55932.2 \\
\hline 5.363 & 55343.6 \\
\hline 5.352 & 55278.9 \\
\hline 4.267 & 46103.8 \\
\hline 4.310 & 46475.6 \\
\hline 4.383 & 47187.0 \\
\hline 5.930 & 59904.7 \\
\hline 5.851 & 59412.8 \\
\hline 5.832 & 59173.5 \\
\hline 5.957 & 60144.4 \\
\hline 5.454 & 56114.0 \\
\hline 5.466 & 56299.7 \\
\hline 5.466 & 56299.7 \\
\hline 5.506 & 56623.9 \\
\hline 5.044 & 52709.4 \\
\hline 5.016 & 52437.7 \\
\hline 5.049 & 52740.2 \\
\hline 5.029 & 52630.7 \\
\hline 4.378 & 47034.0 \\
\hline 4.354 & 46892.6 \\
\hline 4.343 & 46806.1 \\
\hline 4.338 & 46854.6 \\
\hline 4.192 & 45513.3 \\
\hline 4.348 & 45453.6 \\
\hline 3.923 & 43331.9 \\
\hline 3.674 & 41225.7 \\
\hline 3.751 & 41911.0 \\
\hline 3.105 & 35799.2 \\
\hline 3.094 & 35812.6 \\
\hline 2.401 & 28981.0 \\
\hline
\end{tabular}

\begin{tabular}{|c|c|}
\hline \multicolumn{2}{|c|}{$\begin{array}{l}\text { Pure R123 } \\
\text { File: } 123 \text { cond.dat (cont.) }\end{array}$} \\
\hline$\Delta T_{s}(\mathrm{~K})$ & $q^{\prime \prime}\left(\mathrm{W} / \mathrm{m}^{2}\right)$ \\
\hline 2.335 & 28561.8 \\
\hline 1.860 & 23681.0 \\
\hline 1.822 & 23279.7 \\
\hline 0.623 & 10223.8 \\
\hline 5.991 & 60429.3 \\
\hline 5.996 & 60379.0 \\
\hline 5.989 & 60478.7 \\
\hline 5.982 & 60439.4 \\
\hline 5.713 & 58315.1 \\
\hline 5.720 & 58241.3 \\
\hline 5.731 & 58308.8 \\
\hline 5.752 & 58512.8 \\
\hline 5.160 & 53568.4 \\
\hline 5.126 & 53329.7 \\
\hline 5.129 & 53387.5 \\
\hline 5.154 & 53620.4 \\
\hline 4.494 & 47855.6 \\
\hline 4.481 & 48024.5 \\
\hline 4.456 & 47627.3 \\
\hline 3.984 & 43560.5 \\
\hline 3.918 & 43075.1 \\
\hline 3.928 & 43236.8 \\
\hline 3.761 & 41795.6 \\
\hline 3.772 & 41826.9 \\
\hline 3.759 & 41814.4 \\
\hline 3.592 & 40257.2 \\
\hline 3.553 & 39913.6 \\
\hline 3.028 & 35056.3 \\
\hline 3.016 & 34987.8 \\
\hline 2.698 & 32013.2 \\
\hline 2.665 & 31629.6 \\
\hline 2.310 & 28294.7 \\
\hline 1.808 & 23441.8 \\
\hline 1.808 & 23441.8 \\
\hline 1.799 & 23209.8 \\
\hline 2.122 & 26246.1 \\
\hline 2.030 & 25465.1 \\
\hline 2.020 & 25372.3 \\
\hline 2.077 & 25899.1 \\
\hline 1.894 & 24116.2 \\
\hline 1.877 & 23902.7 \\
\hline 1.725 & 22470.9 \\
\hline 1.787 & 23092.8 \\
\hline 1.688 & 22043.1 \\
\hline 1.556 & 20782.6 \\
\hline 1.418 & 19256.2 \\
\hline 1.026 & 14917.6 \\
\hline 1.050 & 15126.6 \\
\hline 0.733 & 11480.9 \\
\hline 0.697 & 11132.4 \\
\hline 0.683 & 10951.5 \\
\hline 0.677 & 10766.0 \\
\hline
\end{tabular}




\begin{tabular}{|l|l|}
\hline 0.530 & 8796.9 \\
\hline 0.404 & 6992.7 \\
\hline 0.527 & 8704.8 \\
\hline 0.527 & 8704.8 \\
\hline 0.482 & 8262.9 \\
\hline 0.386 & 6924.4 \\
\hline 0.366 & 6504.3 \\
\hline 0.383 & 6511.2 \\
\hline 0.339 & 6279.1 \\
\hline 0.336 & 6085.2 \\
\hline 0.295 & 5682.1 \\
\hline 0.281 & 5287.9 \\
\hline 0.268 & 5189.3 \\
\hline 0.215 & 4477.2 \\
\hline 0.246 & 4780.3 \\
\hline 0.103 & 2569.2 \\
\hline 0.085 & 2364.5 \\
\hline 0.090 & 2424.2 \\
\hline 0.093 & 2512.2 \\
\hline
\end{tabular}

\begin{tabular}{|c|c|}
\hline \multicolumn{2}{|c|}{$\begin{array}{c}\text { R123/isopentane } \\
(99.5 / 0.5) \\
\text { File: } 123 \text { iscd.dat (cont.) }\end{array}$} \\
\hline$\Delta T_{s}(\mathrm{~K})$ & $q^{\prime \prime}\left(\mathrm{W} / \mathrm{m}^{2}\right)$ \\
\hline 3.271 & 35294.5 \\
\hline 3.032 & 33113.6 \\
\hline 2.287 & 27157.1 \\
\hline 2.324 & 27530.3 \\
\hline 2.440 & 28504.4 \\
\hline 2.438 & 28640.6 \\
\hline 2.815 & 31898.3 \\
\hline 2.778 & 31620.0 \\
\hline 2.760 & 31386.5 \\
\hline 2.762 & 31458.7 \\
\hline 2.534 & 29417.0 \\
\hline 2.588 & 29801.8 \\
\hline 2.179 & 25948.4 \\
\hline 2.160 & 25888.1 \\
\hline 2.186 & 26194.0 \\
\hline 2.226 & 26399.4 \\
\hline 2.087 & 24932.3 \\
\hline 1.618 & 20129.0 \\
\hline 1.710 & 21314.0 \\
\hline 1.224 & 15732.0 \\
\hline 1.143 & 15154.3 \\
\hline 0.883 & 11577.0 \\
\hline 0.332 & 4774.6 \\
\hline 0.127 & 1135.6 \\
\hline 5.852 & 57785.3 \\
\hline 5.822 & 57778.6 \\
\hline 5.814 & 57713.2 \\
\hline 5.801 & 57694.0 \\
\hline 4.830 & 48852.2 \\
\hline 4.847 & 48800.5 \\
\hline 4.752 & 48712.9 \\
\hline 4.730 & 48578.1 \\
\hline 4.515 & 46118.6 \\
\hline 4.496 & 46816.2 \\
\hline 4.526 & 47063.6 \\
\hline 4.515 & 46786.4 \\
\hline 4.320 & 45115.5 \\
\hline 4.293 & 44859.5 \\
\hline 4.345 & 45448.1 \\
\hline 4.362 & 45615.8 \\
\hline 4.094 & 43101.7 \\
\hline 4.086 & 42877.5 \\
\hline 4.085 & 43076.7 \\
\hline 4.070 & 43056.8 \\
\hline 3.878 & 41346.9 \\
\hline 3.891 & 41389.6 \\
\hline 3.874 & 41093.1 \\
\hline 3.865 & 41218.7 \\
\hline
\end{tabular}


Table 3 Number of test days and data points

\begin{tabular}{|l|c|c|}
\hline Fluid (\% mass) & Number of days & Number of data points \\
\hline R123/isopentane $(99.5 / 0.5)$ & 5 & 72 \\
\hline R123 & 5 & 123 \\
\hline
\end{tabular}

Table 4 Constants for.cubic condensation fits for integral-trapezoidal-fin

$$
\Delta T_{s}=B_{0}+B_{1} q^{\prime \prime}+B_{2} q^{\prime \prime 2}+B_{3} q^{\prime \prime 3}
$$

$\Delta T_{s}$ in Kelvins and $q^{\prime \prime}$ in $\mathrm{W} / \mathrm{m}^{2}$

\begin{tabular}{|l|c|c|c|c|c|}
\hline Fluid & $\mathrm{B}_{0}$ & $\mathrm{~B}_{1}$ & $\mathrm{~B}_{2}$ & $\mathrm{~B}_{3}$ \\
\hline R123/isopentane $(99.5 / 0.5)$ & $0.12 \mathrm{~K} \leq \Delta T_{s} \leq 6.2 \mathrm{~K}$ & 0.0566349 & $5.69407 \times 10^{-5}$ & $1.13360 \times 10^{-9}$ & $-6.87274 \times 10^{-15}$ \\
\hline $\mathrm{R} 123$ & $0.10 \mathrm{~K} \leq \Delta T_{s} \leq 6.0 \mathrm{~K}$ & -0.0758275 & $6.17103 \times 10^{-5}$ & $9.19939 \times 10^{-10}$ & $-4.65887 \times 10^{-15}$ \\
\hline
\end{tabular}




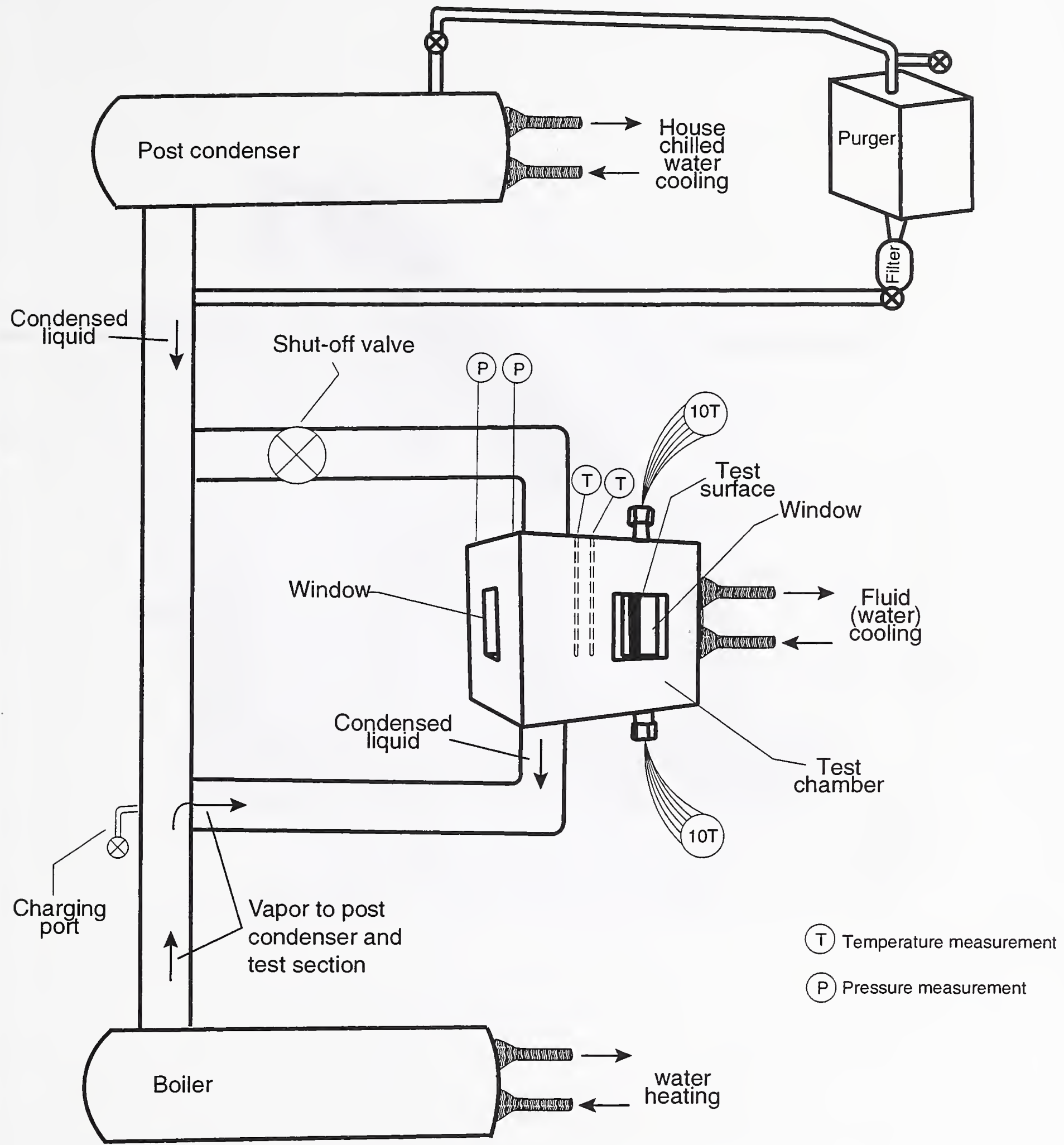

Fig. 1 Schematic of condenser test apparatus 


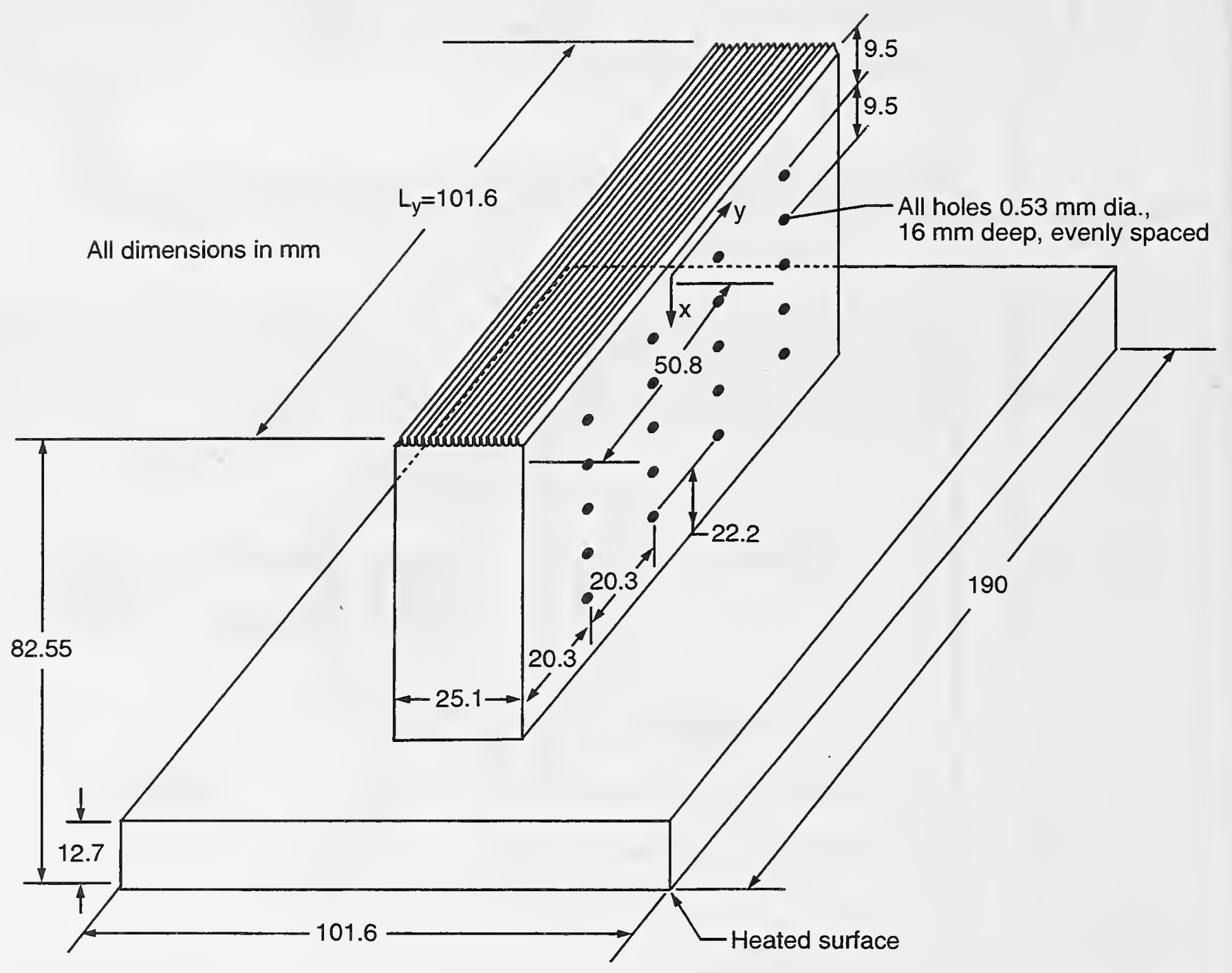

Fig. 2 OFHC copper trapezoidal-fin test plate and thermocouple coordinate system 


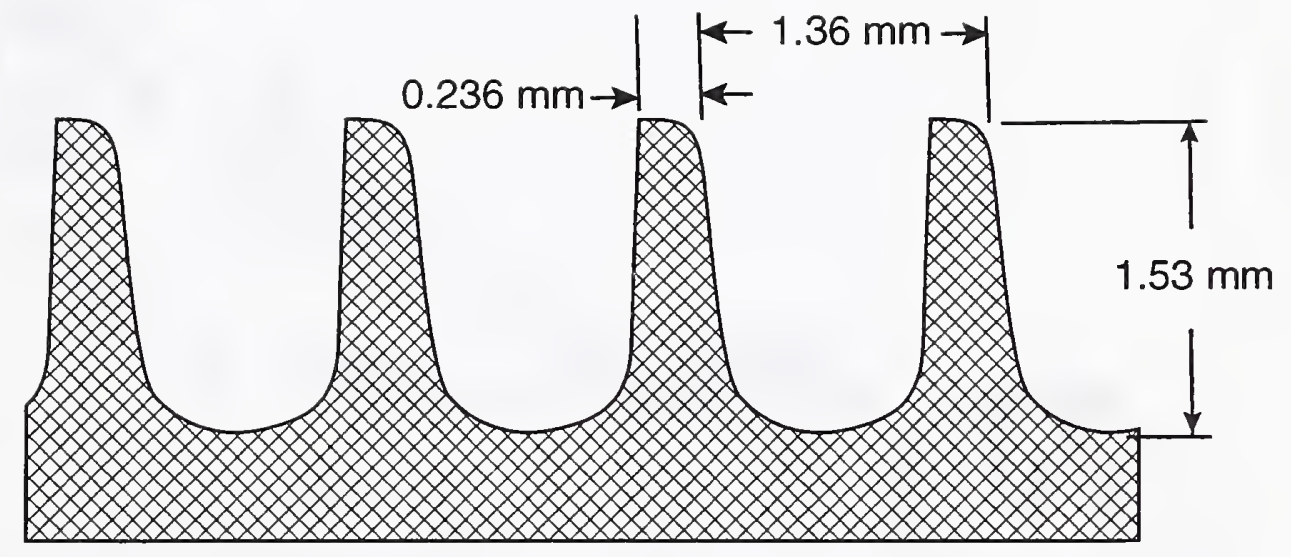

Fig. 3 "Drawing of trapezoidal-fin cross section 


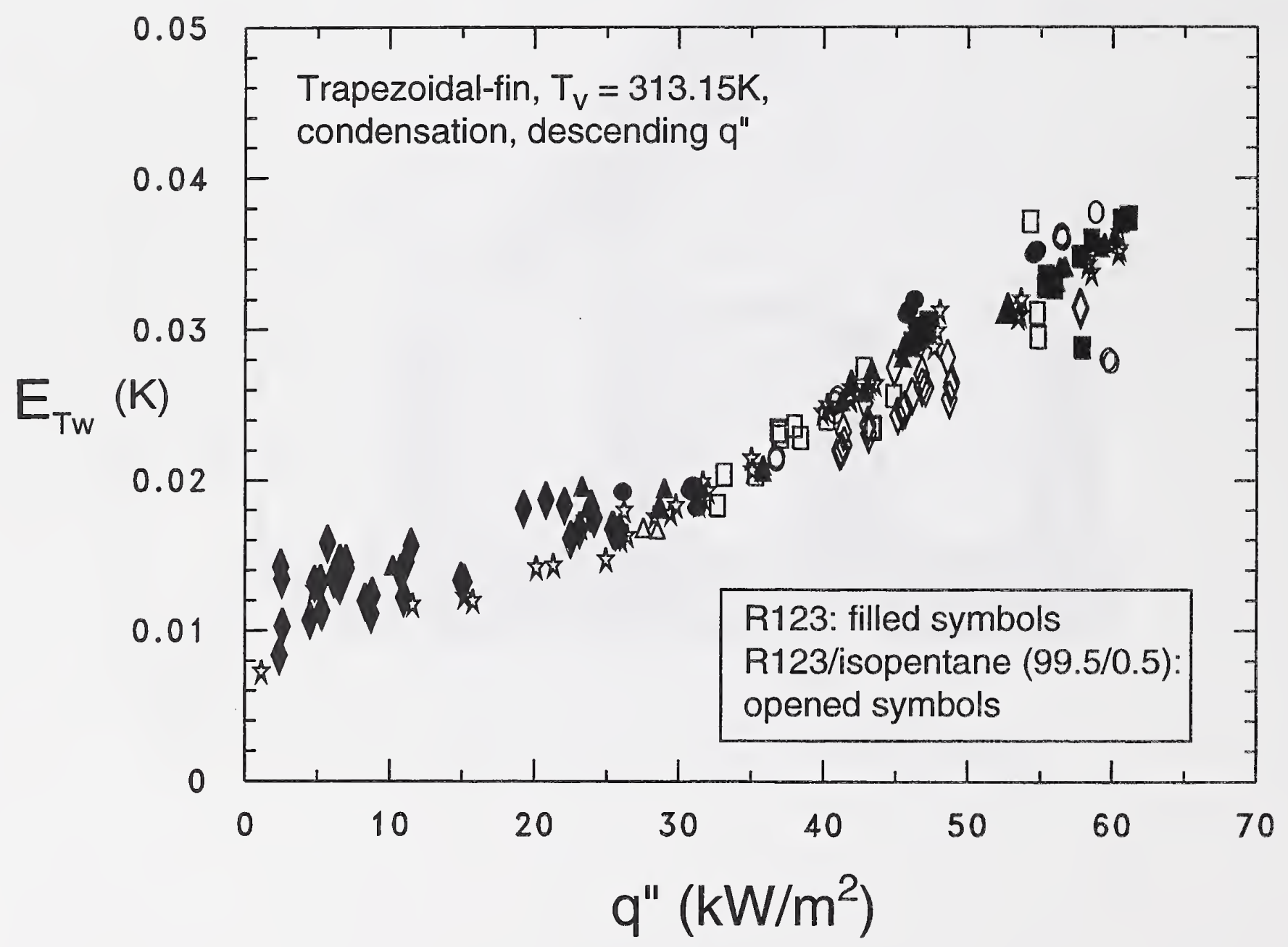

Fig. 4 Uncertainty in the temperature of the surface at the root of the fin for $99.5 \%$ confidence 


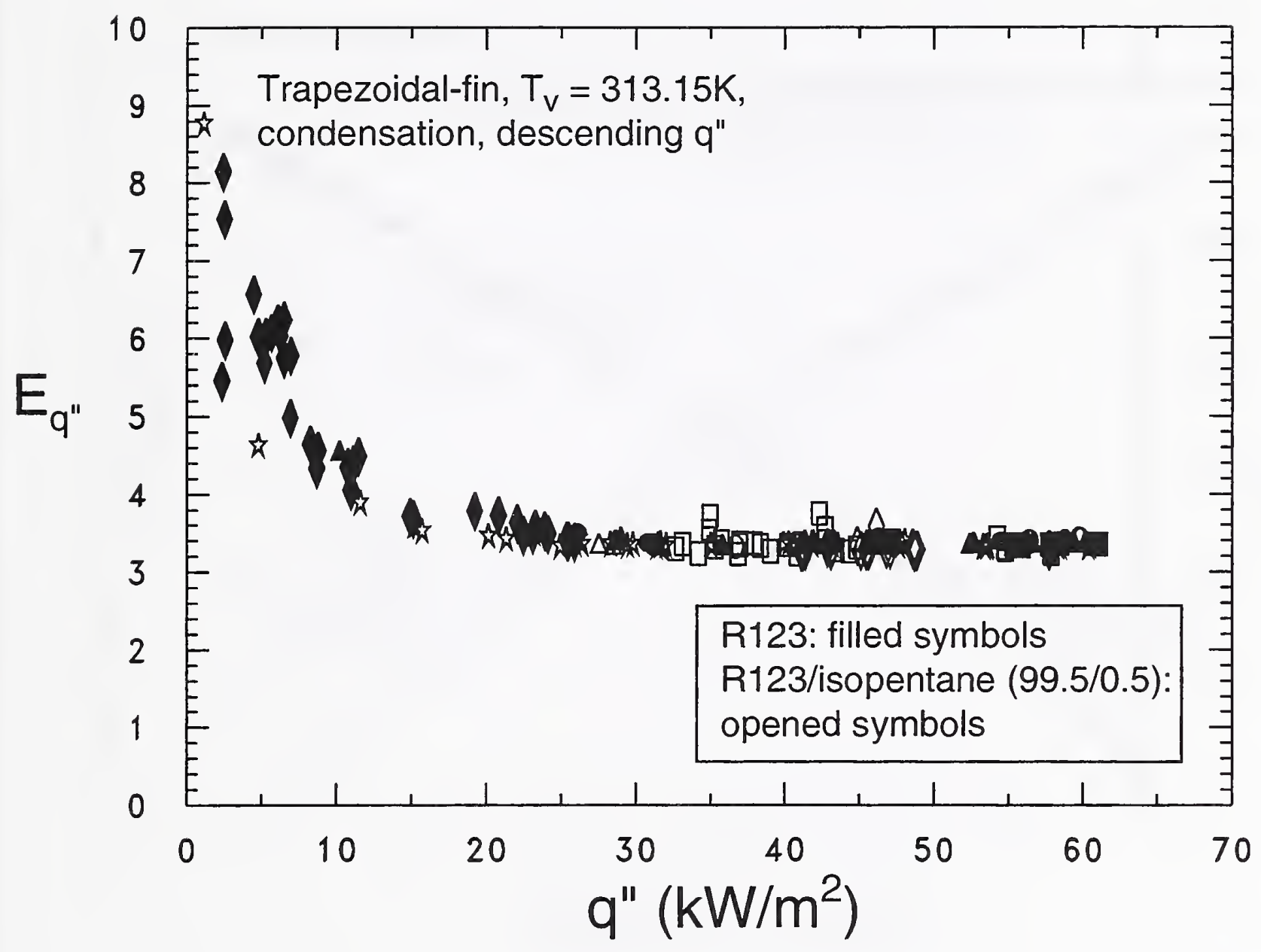

Fig. 5 Percent uncertainty of the heat flux for $95 \%$ confidence 


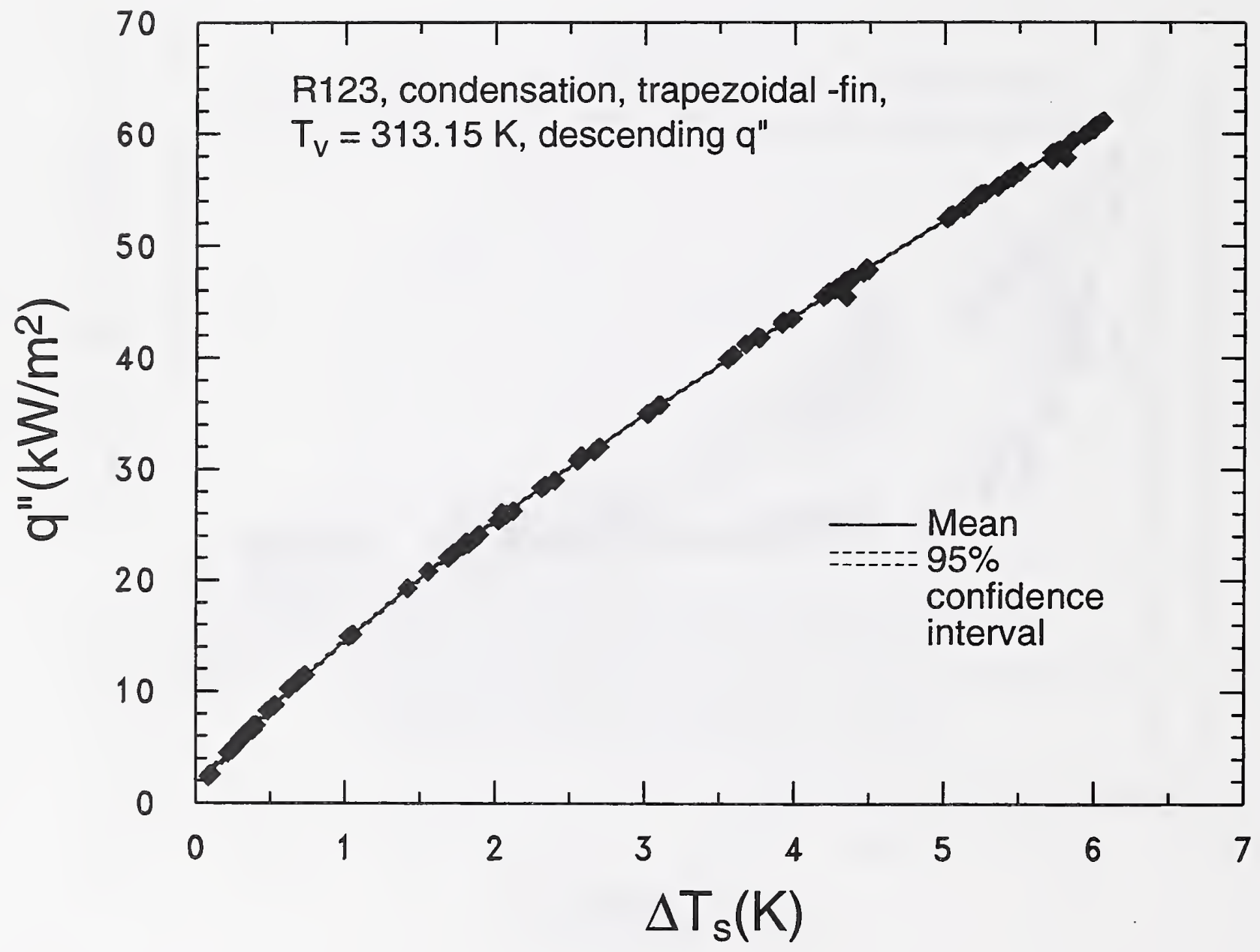

Fig. 6 Measured heat flux versus the measured wall temperature difference for pure R123 


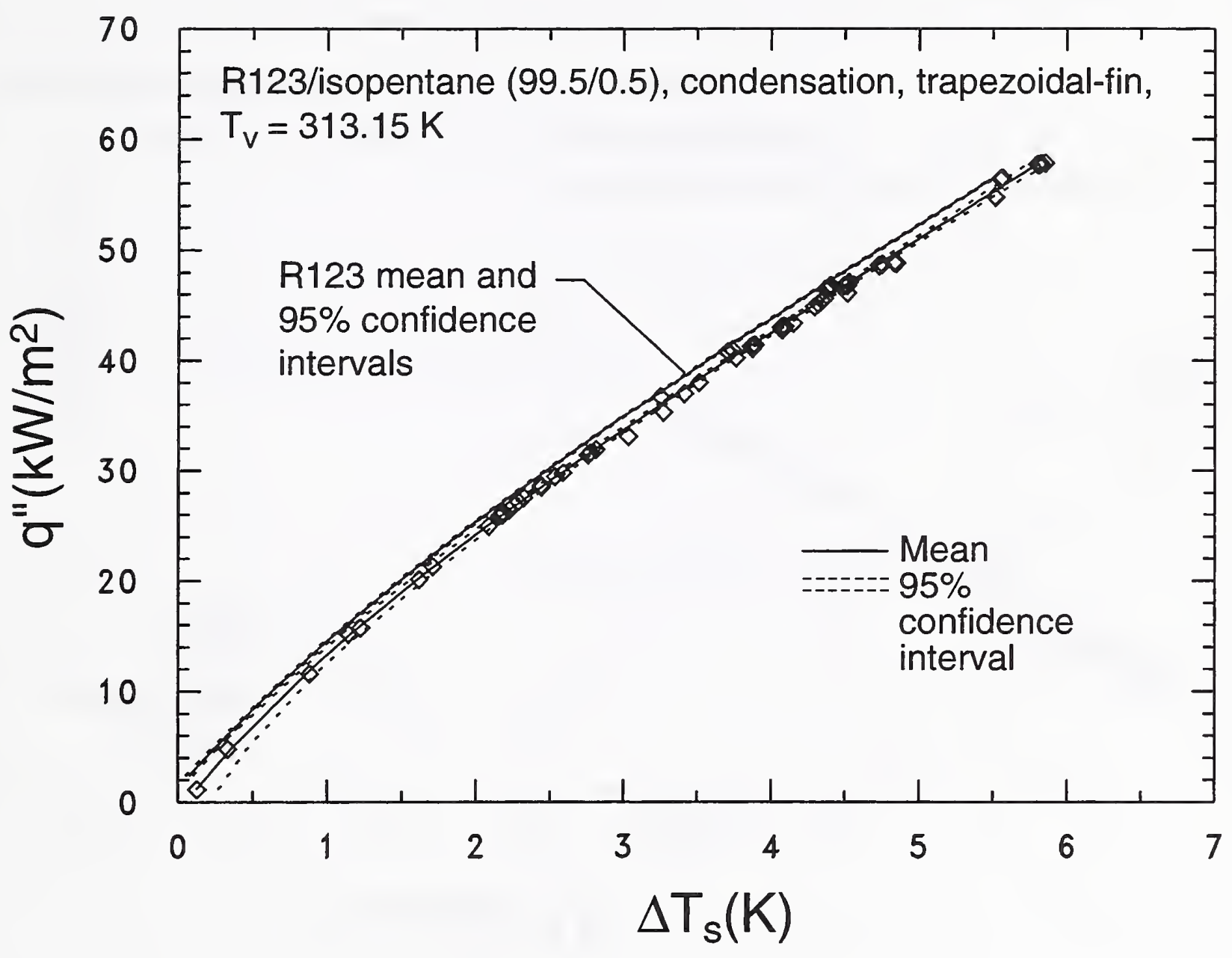

Fig. 7 Measured heat flux versus the measured wall temperature difference for R123/isopentane (99.5/0.5) 


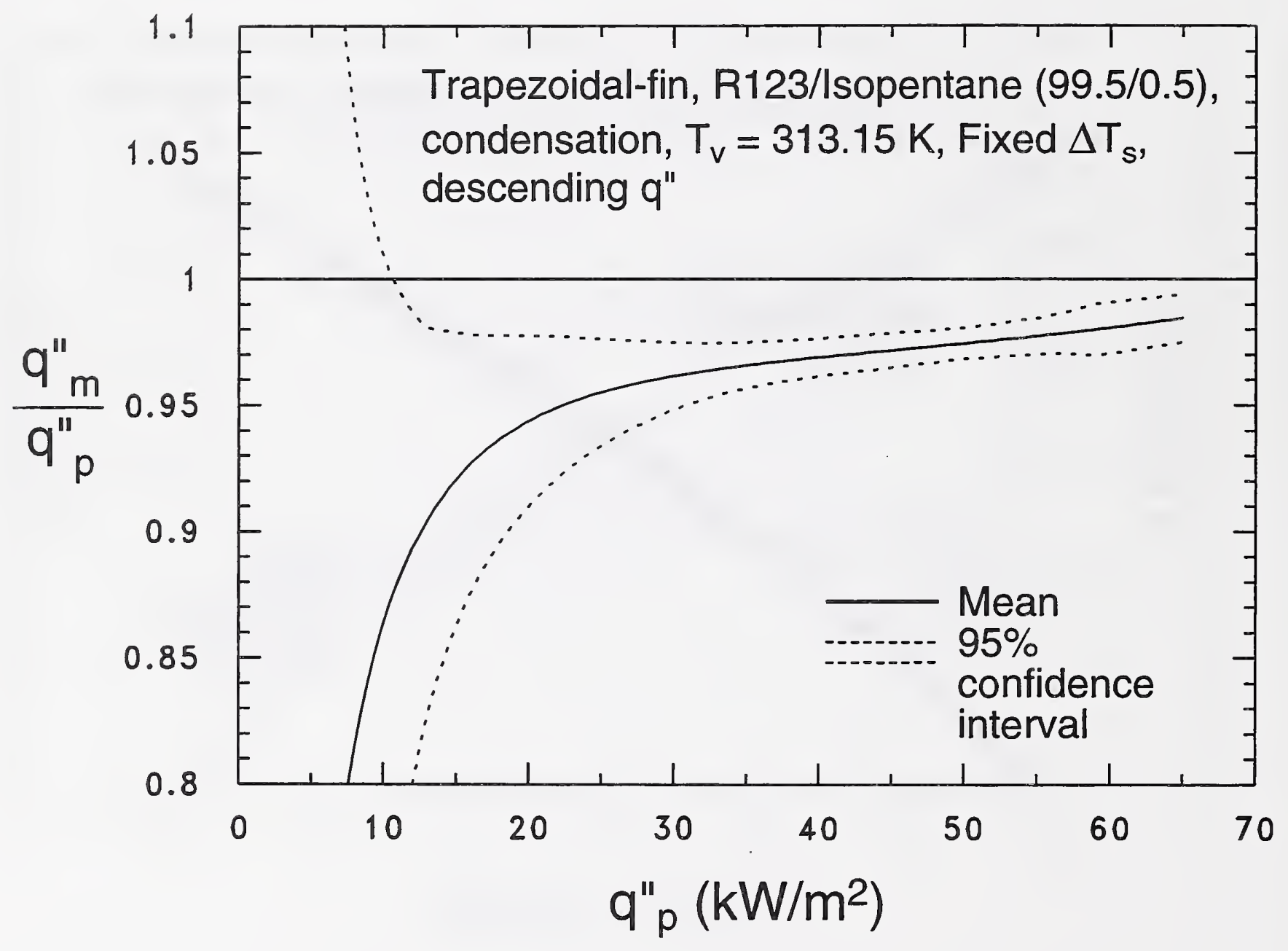

Fig. 8 Relative heat flux between R123/isopentane (99.5/0.5) and pure R123 


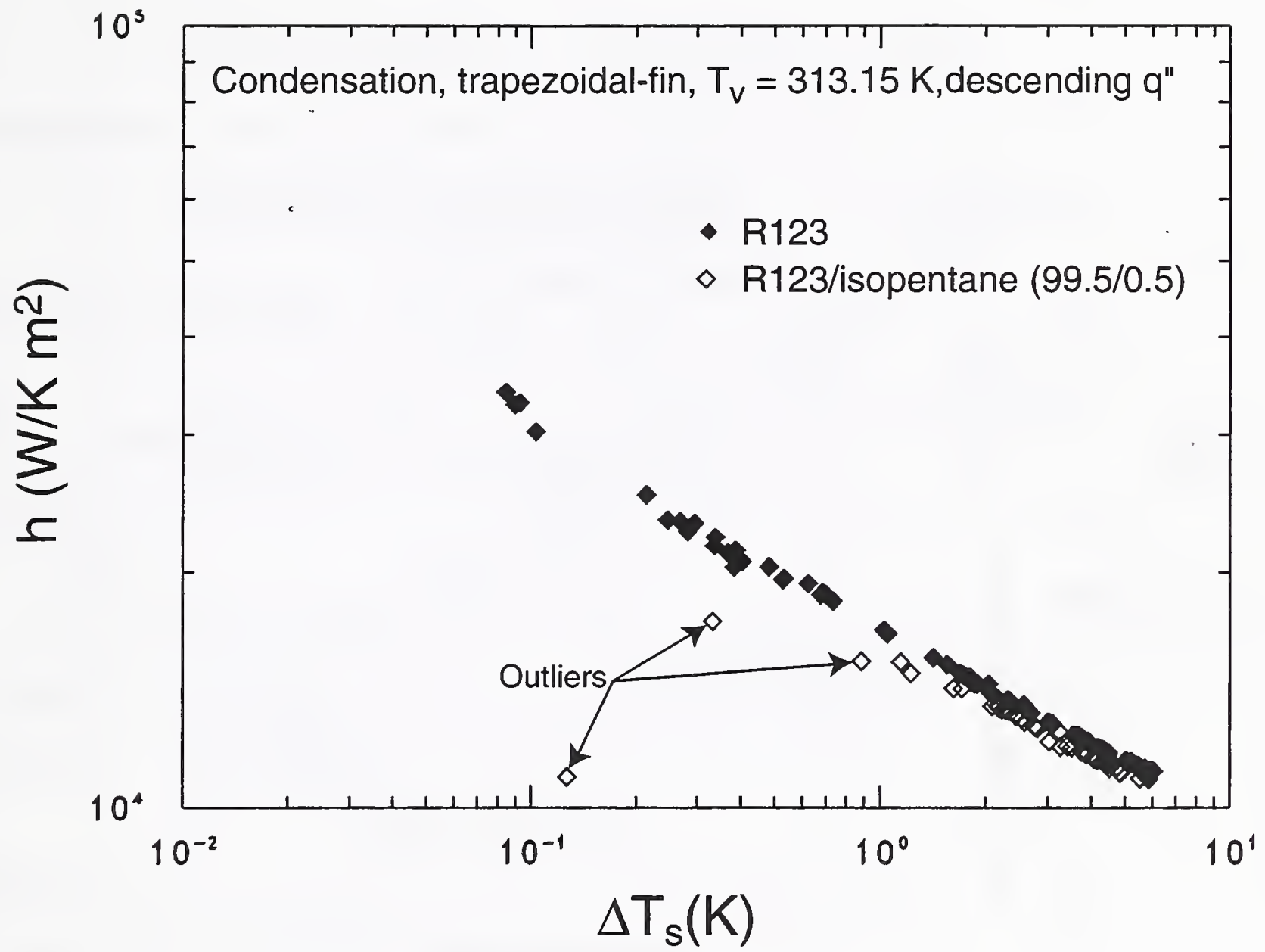

Fig. 9 Condensation heat transfer coefficient for R123 and R123/isopentane (99.5/0.5) 


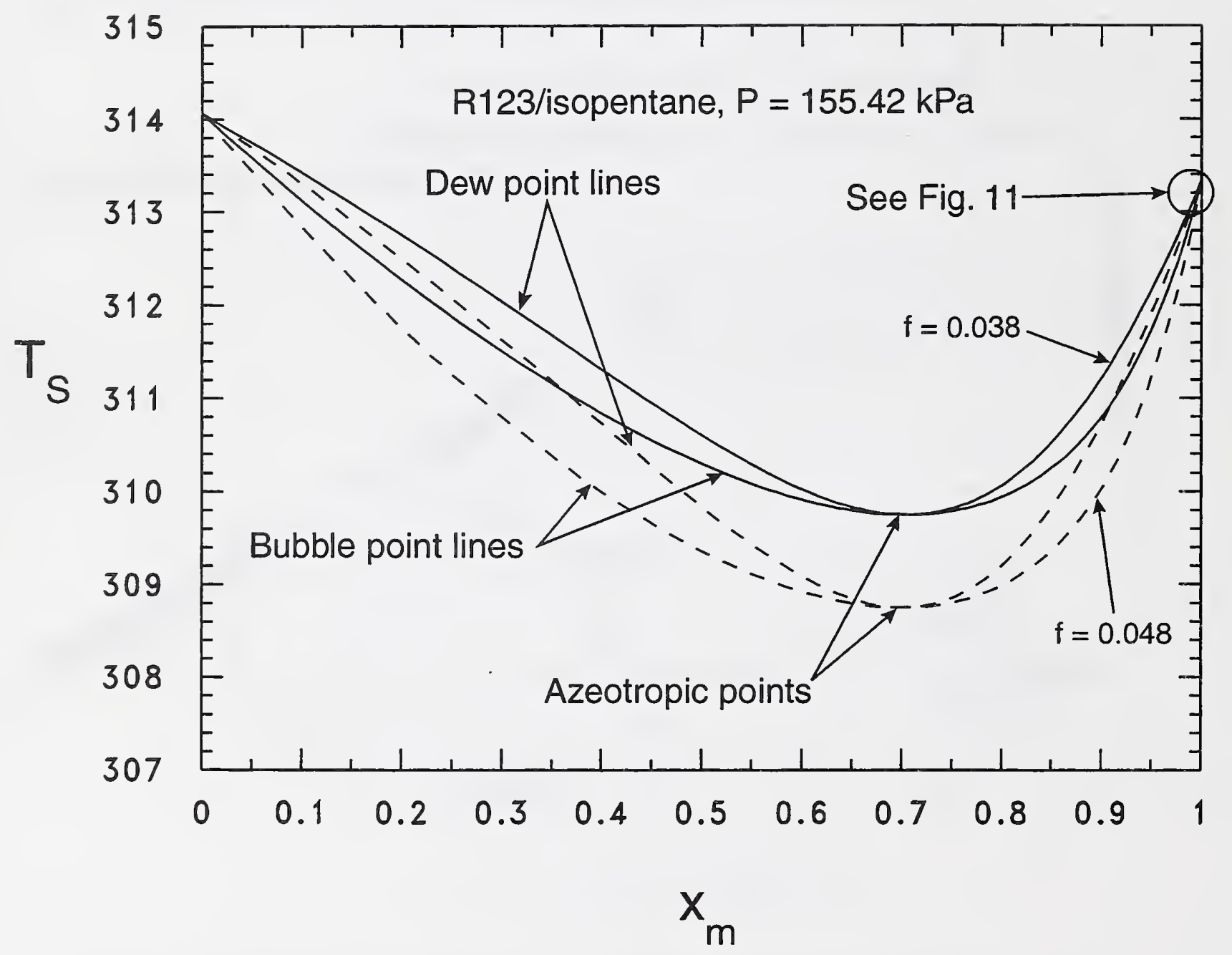

Fig. 10 Equilibrium phase diagram for R123/isopentane at $155.42 \mathrm{kPa}$ 


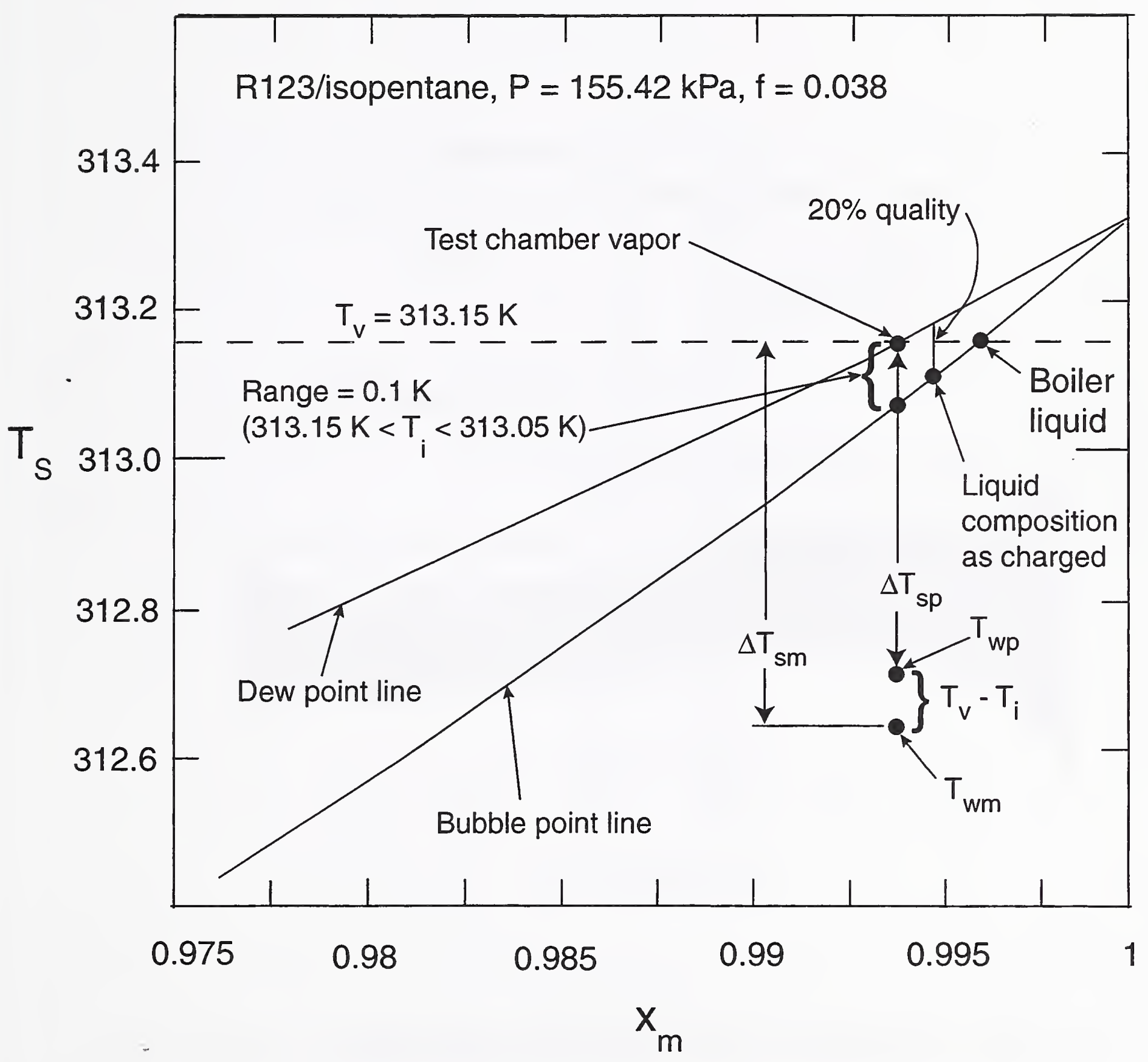

Fig. 11 Focused mass fraction range of the R123/isopentane equilibrium diagram for $f=0.038$ 


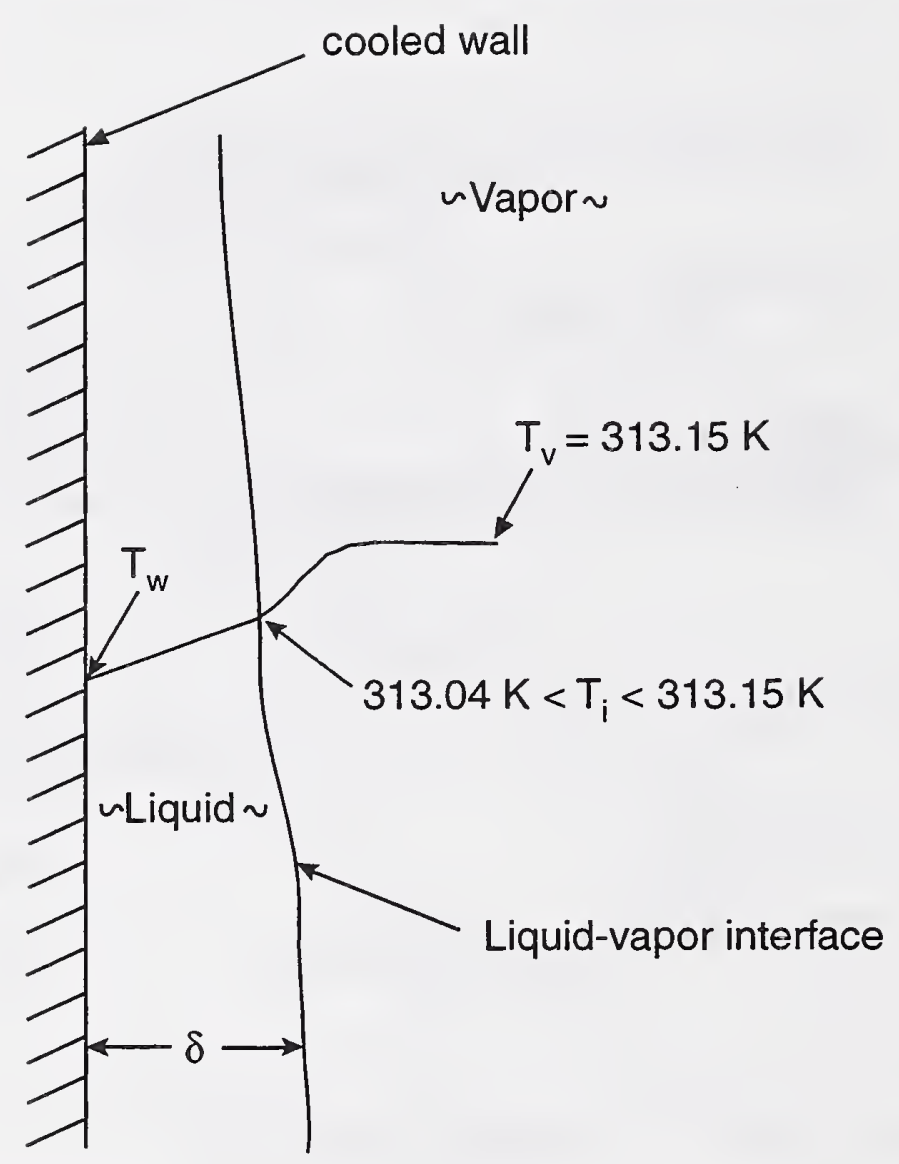

Fig. 12 Cross section of a condensing liquid film on a vertical plate 


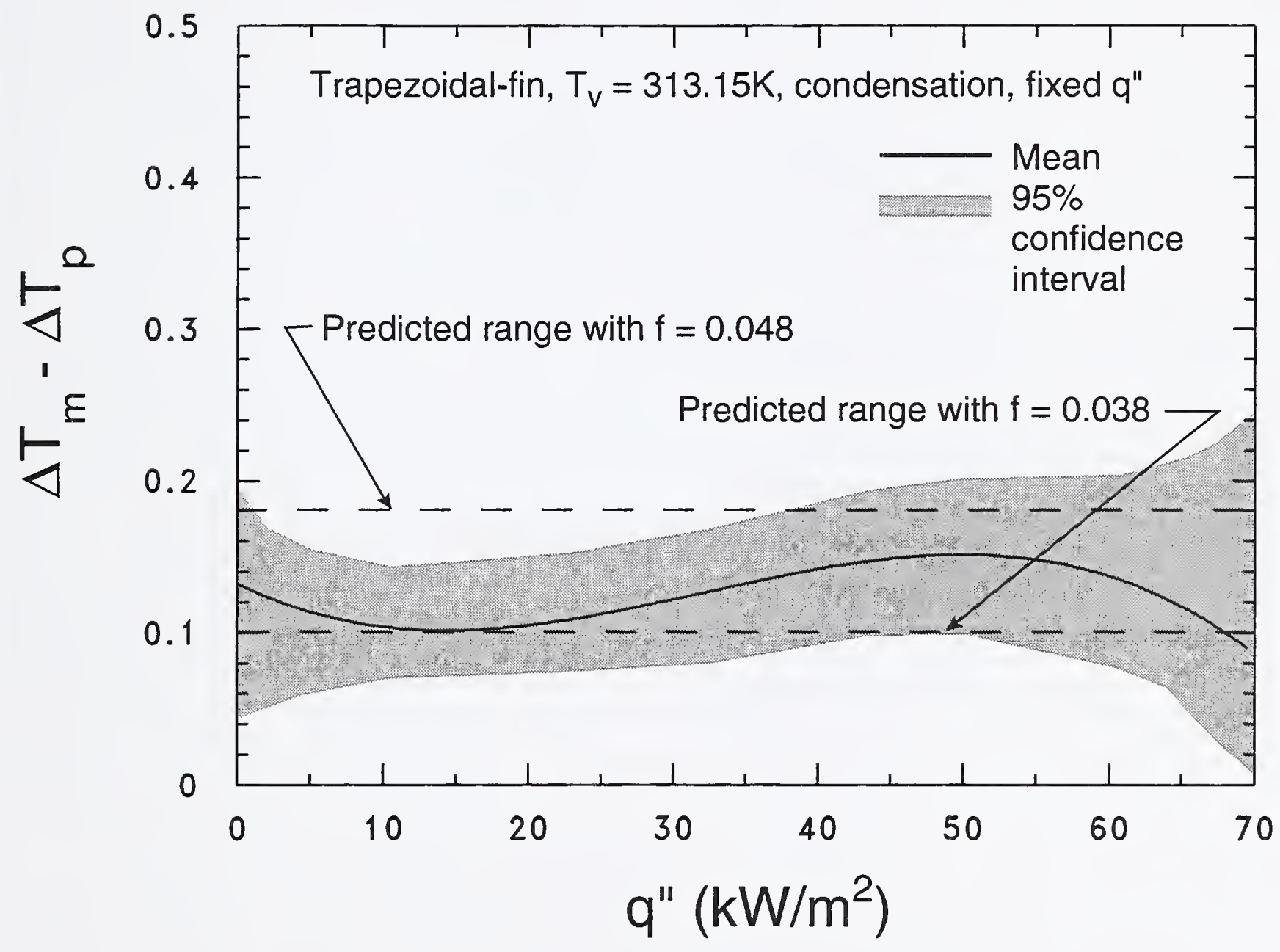

Fig." 13 Difference in the driving temperature differences between R123/isopentane and pure R123 




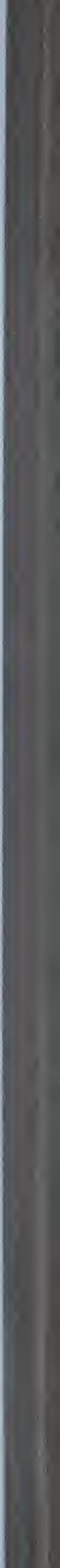

